\title{
Pölymer Flooding: Appraisal of Four Different Field Projects in Germany
}

\author{
* Kleinitz W., ** Littmann W. \\ * Preussag Energie GmbH., Germany \\ ** Littmann Consulting, Germany
}

\begin{abstract}
Copyright 1995, Stearing Committee of the European IOR - Symposium.
This paper was presented at the 8th. European IOR - Symposium in Vienna, Austria, May 15 - 17, 1896

This paper was selected for presentation by the Steering Committee, folfowing review of information contained in an abetract

submitted by the author(s). The paper, as presented has not been reviewed by the Steering Committee.
\end{abstract}

\begin{abstract}
Preussag accomplished four polymer flood projects during the last 10 years in their oil fields in Germany. In three projects (Eddesse-Nord, Vorhop-Knesebeck and Scheerhorn) xanthan broths were used from different producers. The project in the Adorf field was carried out with polyacrylamide.

The projects were performed under different reservoir conditions with respect to temperature $\left(20-70{ }^{\circ} \mathrm{C}\right)$ salinity $(20-200000 \mathrm{ppm})$ and oil viscosity $(3.5$ $30 \mathrm{mPas}$ ).

The projects and their performance are described in detail, regarding the different reservoir conditions and the applied chemical systems. Results on polymer injectability from the field tests are given as well as on polymer stability and adsorption. These field results are compared with laboratory data from the screening and planning phases of the projects.

The incremental oil recovery observed is compared with results from numerical reservoir simulation. At least 2 projects can be regarded as technical successful in terms of incremental oil recovery. The reasons for the partial failure of the other two projects are discussed.
\end{abstract}

\section{Introduction}

The situation in the oil fields operated by Preussag was characterised by increasing water cuts, which had already reached an average value of about $80 \%$ and in some cases up to $97 \%$, which is close to the economic limit. This is why Enhanced Oil Recovery is of major concern for these oil fields.

Besides steam flooding, which was applied in several fields with heavy oils, surfactant flooding and polymer flooding were expected to be the most suitable EOR methods for many of these oil fields. As polymer flooding was regarded as the only chemical method, that is technical and also economical feasible, a xanthan polymer pilot project was started in 1984 in the small oil field Eddesse-Nord.

This reservoir is shallow with depths between 150 to $350 \mathrm{~m}$, which was favourable for drilling and workover, but a constraint for injection pressure, especially during polymer injection. Also temperature is very low with $21^{\circ} \mathrm{C}$, which may lead to high adsorption of chemicals and high levels of bacterial activity. The relatively high clay content of about $10 \%$ was also not very favourable.

At about the same time another polymer flood was started in the Adorf field using polyacrylamide. The reservoir is at a depth of $1350 \mathrm{~m}$, temperature is $68^{\circ} \mathrm{C}$. The initial salinity of the reservoir brine was $250 \mathrm{~g} / \mathrm{L}$. For this reason fresh water was injected as a pre-flush in order to bring down the salinity in the reservoir to a level, where polyacrylamide could be used.

Though the Adorf project was already a large-scale project, based on a proven technology, it was also 
meant as pilot for the rest of the field and the large oil field Scheerhorn.

In both pilot projects no problems occurred in the mixing and injection of the polymer solutions. The injectability of the polymers was monitored in the laboratory, where every batch that was used had to be approved. In these terms both projects could be regarded as technical successfiul, but it was found, that the use of polyacrylamide was not suitable under the conditions in the Adorf and Scheerhorn field. The main reason was not only, that the result of the Adorf project was rather disappointing in terms of incremental oil recovery, but more the problem to handle the large amount of fresh water necessary for flooding using PAA and to dispose the produced reservoir brine.

Therefore the other two projects were carried out using xanthan. The Scheerhorn field is about $1000 \mathrm{~m}$ deep, the reservoir temperature is $49^{\circ} \mathrm{C}$ and the salinity of the reservoir water is $77 \mathrm{~g} / \mathrm{L}$. The viscosity of the Scheerhom oil under reservoir conditions was $30 \mathrm{mPas}$ and the permeability of the sandstone about $2000 \mathrm{mD}$.

The sandstone in the Vorhop-Knesebeck field is at a depth of $1250 \mathrm{~m}$, the salinity of the reservoir water is $210 \mathrm{~g} / \mathrm{L}$. The oil viscosity of $3.5 \mathrm{mPas}$ is relatively low for a polymer flood. The main reason, why this field was chosen, was the sealed fault block and that the project should be a pilot for the North sea fields of Statoil, which was a partner in this project. A xanthan developed and produced by Statoil was used in this project.

\section{Discription of the reservoirs}

In the following a short description of the reservoirs is given. A more detailed overvietw of the Eddesse-Nord and Vorhop-Knesebeck project can be found elsetwhere $[1,2,3]$

\subsection{Eddesse-Nord}

The small block chosen for the pilot project is shown in Fig. 1. This block is separated up dip from the rest of the field by two sealing faults. Nine wells were drilled in this block in total, so that the structure was known quite well. Five of these nine wells were still open and could be used for the polymer project.

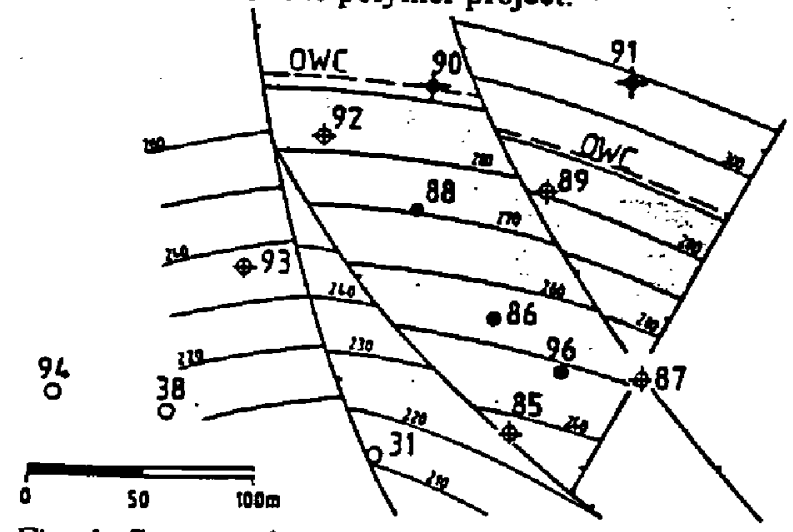

Fig. 1: Structural map of the Eddesse-Nord project area

The reservoir is divided into several different layers from which layer $M$ was chosen for the pilot project.
The reservoir data are summarized in Table 4 together with those of the other projects at the end of the paper. All the wells drilled originally in this block were producing from different layers. Therefore in primary and secondary operations oil was produced only from well 90 , which was because of the down dip position of this well not the optimum. Only during a short period water was injected into well 91 to maintain the reservoir pressure. Due to the weak aquifer during primary production the pressure then fell below the bubble point and a secondary gas cap developed in the up dip part of the structure. Though well 90 is located near the oil water contact it could be produced at water cuts of $50-70 \%$ at low rates for a long period. Cumulative production in 1984 was $7085 \mathrm{~m}^{3}$ tank oil or $35 \%$ of the original oil in place.

Well 96 was drilled in the up dip part of the reservoir before the polymer flood was started. The well was entirely cored in the reservoir zones in order to get fresh and representative core material for laboratory investigations.

\subsection{Adorf}

The project was performed in a small longly stretched block, having an oil water contact. The oil bearing zones were totally separated from the rest of the field. Five wells were completed in the Bentheim Sandstone, three producers, one injector for polymer $(10)$ and one back-pressure well (H2a) to prevent the flow of polymer into the aquifer. The reservoir depth is $1350 \mathrm{~m}$, the temperature $68^{\circ} \mathrm{C}$. The original reservoir brine had a salinity of $250 \mathrm{~g} / \mathrm{L}$. A structure map of the pilot area is shown in Fig. 2.

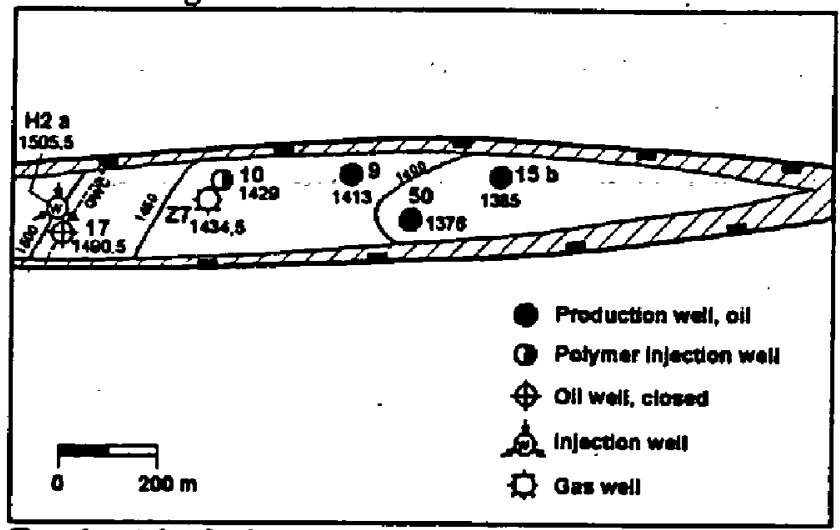

Fig. 2: Adorf pilot area

\subsection{Vorhop-Knesebeck}

The project area in block "H3a upper layer" comprises the wells VK8, VK45, VK48, and VKH3a and was developed in 1959 with well VK8. Since the 8th of May 1982 well VK45 is producing from this unit and since 22nd of December 1982 well VK48.

Due to production in well VK8 the pressure decreased in this unit within 4 years from $13 \mathrm{MPa}$ to the bubble point pressure of $1.5 \mathrm{MPa}$. After that the production mechanisms was solution gas drive and the reservoir pressure stayed constant at the bubble point. This shows that the unit is a confined reservoir with sec. gas cap. 
Since April 1984 the most up dip well VK48 was produced with a steadily decreasing production rate and since August 1984 GOR was increasing.

From October 1984 until March 1985 production was maintained with pressure relief in the casing. Production was no longer possible since March 1985 due to low flowing pressure.

To restart production well $\mathrm{H} 3$ was drilled in October 1986 for water injection. This well did not reach the structure at the desired position, but was landing on the other side of a fault in the neighbour block. So this well was deviated to well $\mathrm{H} 3 \mathrm{a}$ which found the reservoir at the location as shown in Fig. 3.

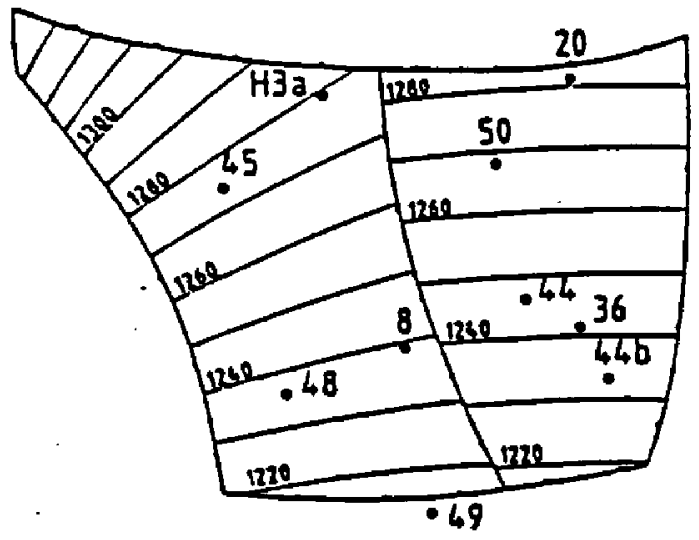

Fig. 3: Structure map of block H3a Vorhop-Knesebeck polymer flood project

Water injection into well VKH3a was started in February 1987 . The reservoir pressure increased very quickly. The production could be started again in July 1987 from well VK48 and VK45 and production from well VK8 could be increased.

Block "H3a upper layer" is confined by sealing faults, but there is a small communication with the lower layer of the block in the North and also, with the block in the East. As long as there is no big pressure difference between these blocks the fluid flow across the faults is supposed to be very small.

\subsection{Scheerhorn}

The oil field Scheerhorn is located in north-west Germany near the Dutch border. Oil is produced from four different zones, where the Bentheim-Sandstone (Valanginian) is the main producing layer. About 120 wells were drilled in the field. For a pilot project a small area in the north, near the transgression was chosen, having the advantage, that the thickness of the reservoir is small $(5 \mathrm{~m})$ as compared to the main area of the field $(30 \mathrm{~m})$. The pilot area is shown in Fig. 4 .

The lower layer of the Bentheim-sandstone was chosen for the pilot. The reservoir depth is about $1080 \mathrm{~m}$ and the temperature $49{ }^{\circ} \mathrm{C}$. The salinity in the different parts of the reservoir varies between 50 and $200 \mathrm{~g} / \mathrm{L}$, as different injection waters were used. from other oil fields as well as fresh water. The salinity development could be used like a tracer to monitor the communication between different wells.

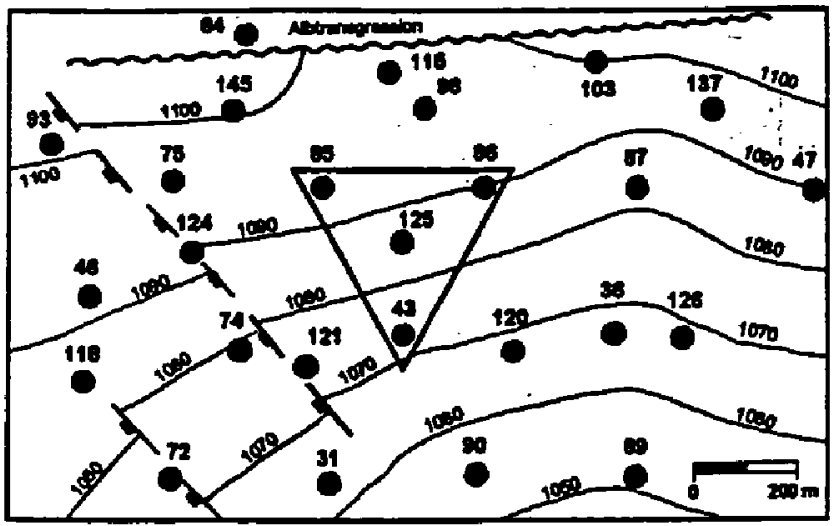

Fig. 4: Pilot area - Scheerhorn

The oil viscosity was $30 \mathrm{mPas}$ under reservoir conditions, the permeability of the sandstone about 2000 $\mathrm{mD}$. Due to the high oil viscosity, the recovery of the oil field was only about $20 \%$ of the OOIP at a water cut of $98 \%$. These are in principal favourable conditions for polymer flooding, as the oil saturation is still high and the mobility ratio may be improved significantly.

\section{Polymer injection}

Before the start of all the polymer projects a thorough screening was performed to find the most suitable polymer with respect to viscosity yield, injectability and cost. Another point was to ensure polymer stability in the reservoir and to minimise adsorption.

\subsection{Eddesse-Nord}

Before polymer injection was started a water preflush of $10300 \mathrm{~m}^{3}$ was injected into well 91 in order to repressurise the reservoir and thus reduce the secondary gas cap and to gain more data by the water flood performance fot the planning of the polymer flood. Formaldehyde was injected together with the water as a tracer and as a biocide for the following polymer slug.

A xanthan polymer solution containing $800-1000 \mathrm{ppm}$ of active xanthan was injected into wells 90 and 91 at a rate of $10-12 \mathrm{~m}^{3} / \mathrm{d}$ in each well. Polymer injection started in November 1985 and ended in May 1988. The injection well head pressure was $1.5-2.0 \mathrm{MPa}$ in well 90 and $1.0 \mathrm{MPa}$ in well 91 . No injectivity problems occurred. Details about polymer mixing, injection and quality control are described elsewhere $[4,5,6]$

The santhan used for the project was produced in a 40 $\mathrm{m}^{3}$ fermentor on a pilot scale by BAYER. The $2 \%$ broth from the fermentor was transported to the field and directly diluted in the injection water to the desired concentration.

The fermentation process for xanthan was improved in order to obtain a product for enhanced oil recovery. This lead to a product with a lower viscosity yield as e.g. xanthans used in other applications but a much better injectability. This was mainly due to the lower pyruvate content. The pyruvate group at the end of one side chain of the molecule is mainly, besides the acetate group, responsible for the anionic character of the makro-molecule. 


\subsection{Adorf}

The polymer that was used was a partially hydrolysed polyacrylamide commercially produced and delivered as an emulsion. The active concentration of the emulsion was $33 \%$.

As for this project polyacrylamide was used, which is very salt sensitive [6], it was necessary to reduce the initial salinity. The reservoir therefore was flooded with fresh water. This water had an hardness corresponding to $16 \mathrm{mg} \mathrm{CaO} / \mathrm{L}$ ( $16^{\circ} \mathrm{dH}$ ). In such a water a polymer solution with a concentration of $800 \mathrm{ppm}$ (active) had a viscosity of $20 \mathrm{mPas}$ at a shear rate of $7 \mathrm{~s}^{-1}$.

\subsection{Vorhop-Knesebeck}

The polymer was produced at the Statoil Biocenter in Stavanger. The xanthan broth came from the fermentor at a concentration of about $3 \%$ active material. As the investment for further concentration of the polymer broth is very high the polymer was shipped at this concentration to Germany.

The polymer was shipped in $23 \mathrm{~m}^{3}$ tank containers from Stavanger to Hamburg. These containers were then transported to the field, where the polymer was drawn directly from the containers and mixed with the injection water. The injection water was the separated water from the oil production. Before the water was mixed with polymer hydrochloric acid, formaldehyde and citric acid were added.

\subsection{Scheerhorn}

In this project a commercial high pyruvate xanthan was used. This and the higher concentration were the main differences to the xanthan used in the other two projects. Due to the higher pyruvic content, the polymer solutions had a higher viscosity yield. Our interpretation for the higher viscosity yield was not a higher molecular weight, but the formation of aggregates of the polymer chains because of the higher charges at the molecule according to the higher pyruvic content. This happened especially in the presence of 2 valent ions as $\mathrm{Ca}^{2+}$. The aggregation of polymer molecules not only led to a higher viscosity yield, but also to a worse injectability, which was still tolerable, but for some batches caused problems.

The mixing and injection scheme was similar to that of the other xanthan projects.

\section{Production performance}

\subsection{Eddesse-Nord}

Production in well 96 was started in March 1985. After producing $1200 \mathrm{~m}^{3}\left(\mathrm{~V}_{\mathrm{n}}\right)$ of gas the well could produce at a rate of $3-4 \mathrm{~m}^{3} / \mathrm{d}$ with little water. As this production rate was too low (only $25 \%$ of the injection rate) and a further acceleration was not possible, well 88 was also put into production in May 1986 and well 86 in March 1987.

In Fig. 5 the water cut developments of well 96 is shown together with the results of a numerical reservoir simulation.
The reservoir simulation was performed with a-black oil simulator and for the polymer prediction a polymer option was used.

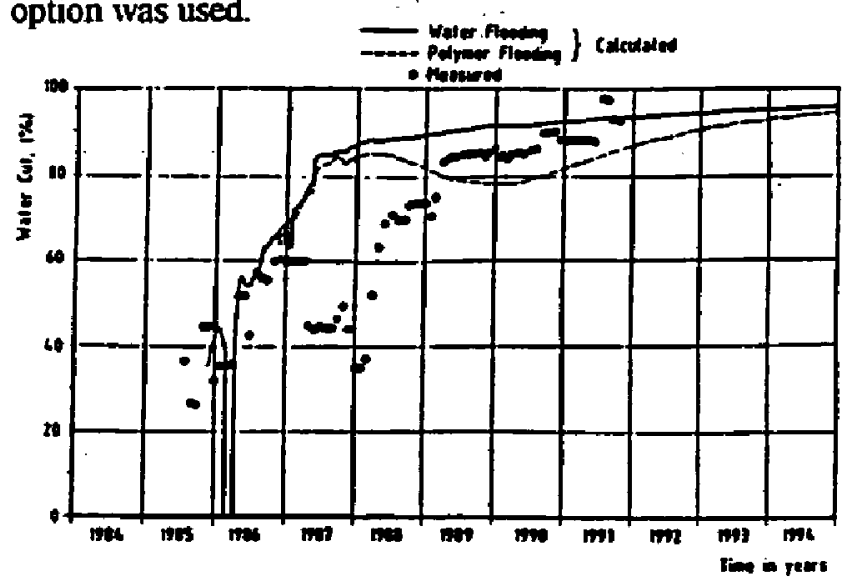

Fig. 5: Response of well 96 to polymer injection Eddesse-Nord

Though well 96 is the most distant from the injectors, a clear response to the polymer flooding could be observed very early on. In the beginning the measured data matched very well with the data predicted for water flooding. A decrease in water cut to $30-40 \%$ could be observed in 1987, when the water cut predicted for water flooding should be around $90 \%$.

A similar behaviour could be observed for well 86 . This well was recompleted into another production zone at the end of 1988.

The simulation further showed, that about $50 \%$ of the injected polymer was lost into the aquifer and therefore only a slug of about $35 \%$ of hydrocarbon filled pore volume was active in the project for displacing the oil. Hence the observed effect in incremental oil recovery is remarkable. Up to the end of $199110850 \mathrm{~m}^{3}$ oil had already been produced, which is more than that what was predicted to be the ultimate recovery for water flooding.

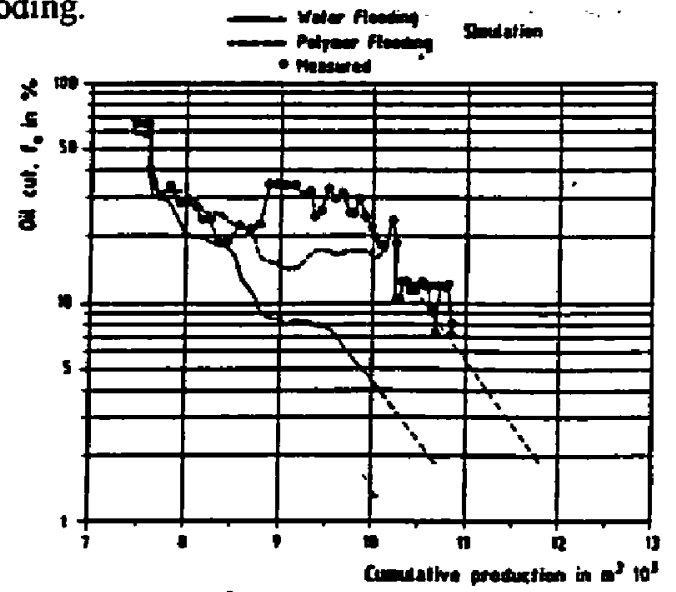

Fig 6: Project performance - Eddesse-Nord. Oil cut vs. cumulative oil production (total block)

The field results are compared with the predictions for water and polymer flooding. The simulation nuns were performed until 1996 using the actual production rates and for further predictions the last actual production rates in the field. As can be seen from Fig. 6 cumulative production in the polymer flood is already higher than what may be extrapolated for water flooding. The 
actual field performance of the polymer flood is also better than the polymer prediction by numerical reservoir simulation: The incremental production by polymer flooding as compared to water injection is between 1000 and $1500 \mathrm{~m}^{3}$, which is $5-7 \%$ of the original oil in place [3].

\subsection{Adorf}

In Fig. 7 the response to polymer flooding in well 9 is shown.

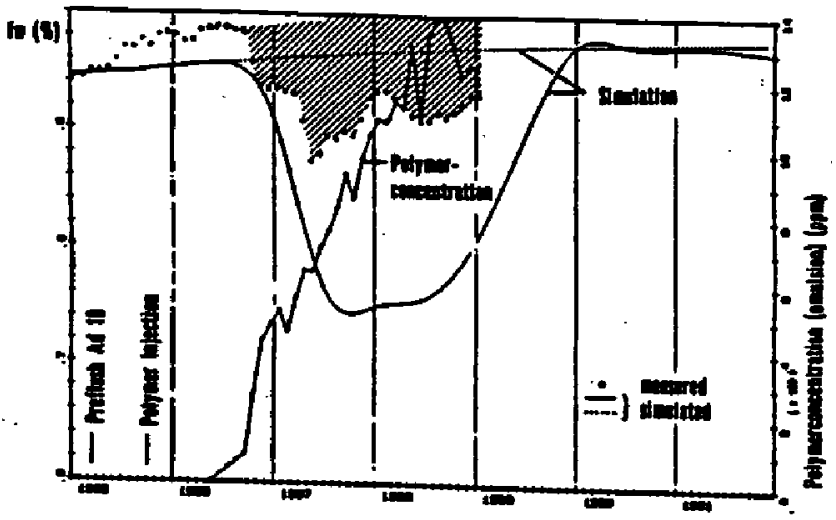

Fig. 7: Response to polymer flooding in well 9 - Adorf

The Figure shows the decrease in salinity and the polymer production. The polymer concentration in the produced water comes up to $1200 \mathrm{ppm}$ (referred to emulsion) or $400 \mathrm{ppm}$ active, which equals $50 \%$ of the injected concentration. Considering dispersion and the salinity development, this means that the adsorption of the polymer is relatively low.

A decrease in water cut also was observed, but it was much lower than predicted by simulation.

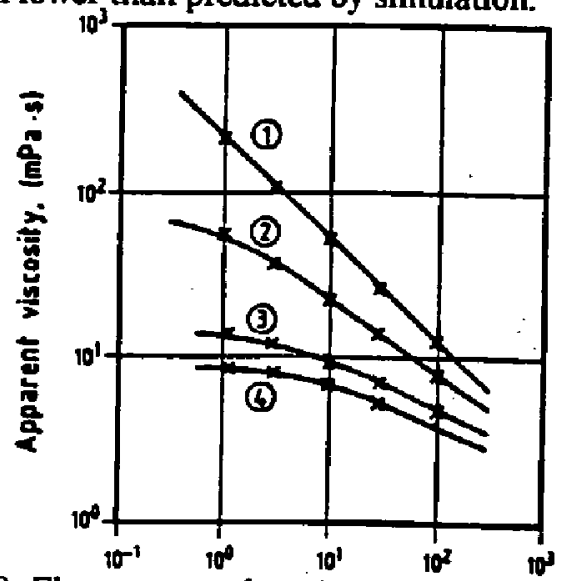

Fig. 8. Flow curves of a solution of $1000 \mathrm{ppm}$ polyacrylanide at different hardnesses of mixing water: 1) $1.6^{\circ} \mathrm{dH}$; 2) $5^{\circ} \mathrm{dH}$; 3) $15^{\circ} \mathrm{dH}$; 4) $25^{\circ} \mathrm{dH}$. ( $\left.{ }^{\circ} \mathrm{dH}=10 \mathrm{mg} \mathrm{CaO} / \mathrm{l}\right)[6]$

The technical performance of the project was very good, no problems occurred, neither in polymer mixing nor in injection. Adsorption of the polymer was low, and an analysis of the produced polymer had shown, that the degree of hydrolysis had increased from $30 \%$ to about $50 \%$, but the polymer was not degraded at all with respect to molecular weight.
The main reason for the poor response can be seen in the fact, that the polymer solution did not have the expected viscosity under reservoir conditions.

In Fig. 8 flow curves of polyacrylamide solutions in different mixing waters are shown. Flow curve 1 corresponds to the mixing water used in Adorf. It is obvious that such a solution is very sensitive to only small changes in hardness.

Calculations and laboratory test performed later showved, that a fresh water being in contact with the minerals in the reservoir should at least have a hardness of 10 . This means, according to Fig. 8, that the viscosity of the polymer solution would only be about $20 \%$ of that one injected at a hardness of 1.6 ${ }^{\circ} \mathrm{dH}$.

This was also found by producing back the polymer solution from the injection well. Table 1 shows the volume produced and the corresponding hardness and viscosity of the polymer solution.

Table 1: Back-production from well 10-Adorf

\begin{tabular}{|c|c|c|}
\hline $\begin{array}{c}\text { cum. produced } \\
\mathrm{m}^{3}\end{array}$ & $\begin{array}{c}\text { hardness } \\
{ }^{\circ} \mathrm{dH}\end{array}$ & $\begin{array}{c}\text { viscosity at } 7^{\mathrm{s}-1} \\
\mathrm{mPas}\end{array}$ \\
\hline 0 & 1.6 & 20 \\
\hline 22 & 6.1 & 4.0 \\
\hline 500 & 8.4 & 4.7 \\
\hline 1315 & 11.2 & 4.1 \\
\hline 1702 & 11.0 & 4.0 \\
\hline
\end{tabular}

These results show, that even when the reservoir brine were displaced effectively, the mineralogy of the reservoir would very quickly bring the hardness to a value of about 10 and thus reduce the viscosity of the polymer solution significantly. A viscosity of about 4 of the polymer solution would explain the lower incremental recovery.

\subsection{Vorhop-Knesebeck}

In Fig. 9 the simulated water cut and the values from the field are plotted for well 45 . This well is the nearest to the injection well and therefore had a very early response. The field values are monthly averages. Well 45 was producing at a $100 \%$ water cut since the beginning of 1990 . This behaviour could not be matched by the simulation. The highest water cut in the simulation was about $98 \%$. A response to polymer flooding in the simulation may be observed in the middle of 1991 with a reduction in water cut as compared to the pure water flood case of about $1.5 \%$.

In the data measured in the field no significant response may be seen. The accuracy of these data is not very high, as the water cut is measured by a very simple volumetric method in a field lab and further these data are averaged by a statistical computer program, so that there are almost only values of $100 \%$.

In Fig. 10 the oil cuts produced in well 45 are plotted as measured in the Preussag main laboratory. These values show a response in the beginning of 1991. The oil cut increased from zero to about $0.5 \%$. This 
decrease in water cut fits well with the values in the simulation. After a workover in well 45 the water cut became again $100 \%$ for about 1 year. In June 1992 oil was produced again. This oil was produced in stable emulsions, which could not be separated easily. This is also the reason why nearly $100 \%$ water cut was found in the field lab.

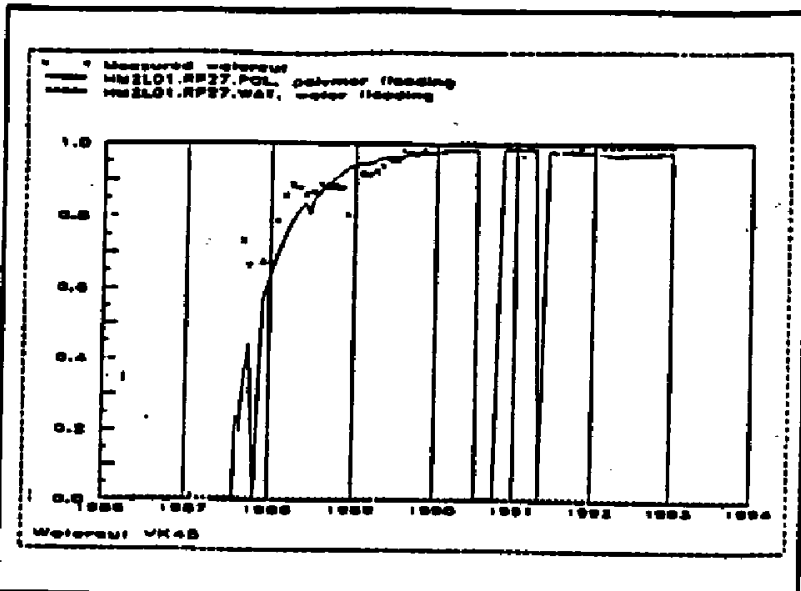

Fig. 9: Water cut of well 45. Simulation and measured field data-Vorhop-Knesebeck

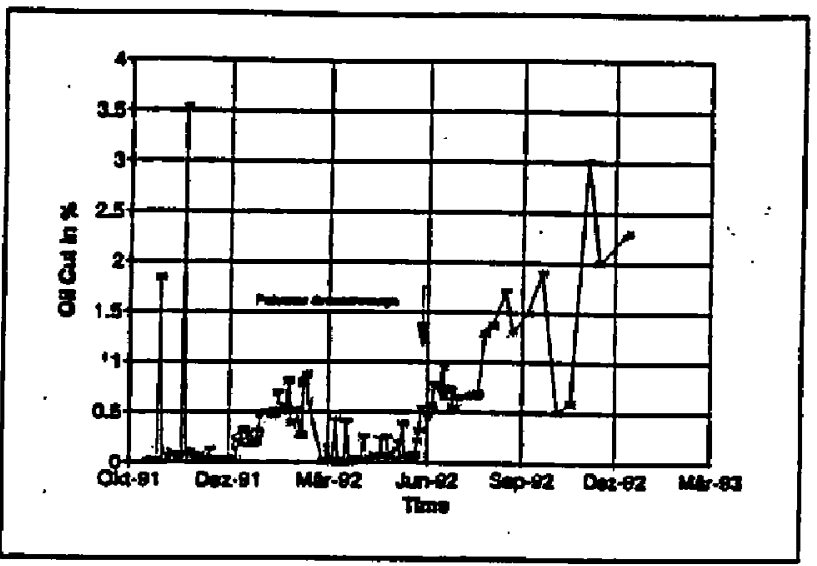

Fig. 10: Oil cut in well 45 as measured in the Preussag laboratory.

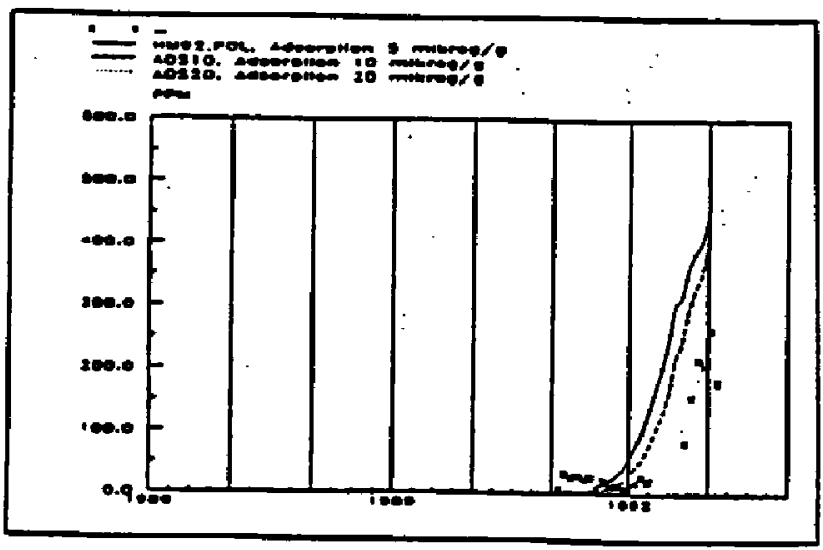

Fig. 11: Polymer concentration in production well 45 , measured and simulated

Until the end of 1992 the oil cut increased to about 2.5 $\%$ and is still increasing.

Polymer breakthrough was in the beginning of 1991 and stayed at a level of about $20 \mathrm{ppm}$ for about one and a half year. At the same time, when oil cut increased the polymer concentration in well 45 also increased. In
July 1992 values of about $150 \mathrm{ppm}$ were measured From viscosity measurement a value of about $200 \mathrm{ppm}$ was determined in December 1992. The simulation was performed with an adsorption of 5,10 and $20 \mu \mathrm{g} / \mathrm{g}$ (Fig. 11). The best fit is obtained with an adsorption of $20 \mu \mathrm{g} / \mathrm{g}$, what is relatively small as compared to laboratory data from literature [6].

The concentration of xanthan may also be determined by viscosity measurement of the produced water, if the concentration is sufficiently high. In Table 2 values measured at samples from well 45 are listed. The concentrations are determined by using a calibration curve.

Table 2: Viscosities of produced water from well 45 Vorhop-Knesebeck $\left(7 s^{3}\right)$

\begin{tabular}{|c|c|c|}
\hline Date & $\begin{array}{c}\text { Viscosity } \\
.\end{array}$ & $\begin{array}{c}\text { Xanthan } \\
\text { concentration }\end{array}$ \\
\hline & mPas@20 0 & ppm \\
\hline injected & 6.70 & 400 \\
\hline 24.11 .92 & 2.98 & 160 \\
\hline 01.12 .92 & 2.96 & 160 \\
\hline 11.12 .92 & 3.30 & 200 \\
\hline 18.12 .92 & 3.40 & 200 \\
\hline
\end{tabular}

The total performance of the project in terms of incremental oil recovery was not as good as expected. The main reason was that the description of the reservoir had to be changed during the project. This resulted in a higher oil recovery during water flood, so that the amount of oil, that was produced incrementally during the project could not totally be credited to the polymer flooding. The incremental oil recovery, that can be calculated so far is about $3 \%$ of the OOIP. In total the project can be regarded as technical successful especially to the fact, that polymer adsorption of about $20 \mu \mathrm{g} / \mathrm{g}$ is much lower than expected from laboratory measurement (at least $70 \mu \mathrm{g} / \mathrm{g}$ ).

\subsection{Scheerhom}

In Fig. 12 the response of well 85 is shown. This well shows a clear response to polymer injection, but it was lower than expected. From simulation nuns an incremental oil recovery of $15 \%$ was expected for the pilot area, but only $3 \%$ was actually reached.

There were two main reasons found for this result. The first is the polymer itself. It was already mentioned, that the vanthan used in this 'project was substantially different from that one used in the other 2 projects. Due to economical reasons a product with a higher viscosity yield was used. This product did not have the same stability as the others.

This was found in the lab, but also in the field. From the injection well a sample was taken at the.well head and afterwards the well was flowing back. About $30 \mathrm{~m}^{3}$ of xanthan solution could be produced from the injection well. In Table 3 the viscosities of these samples are given. A decrease in viscosity could be 
observed already after a short time, when the polymer had entered the reservoir.

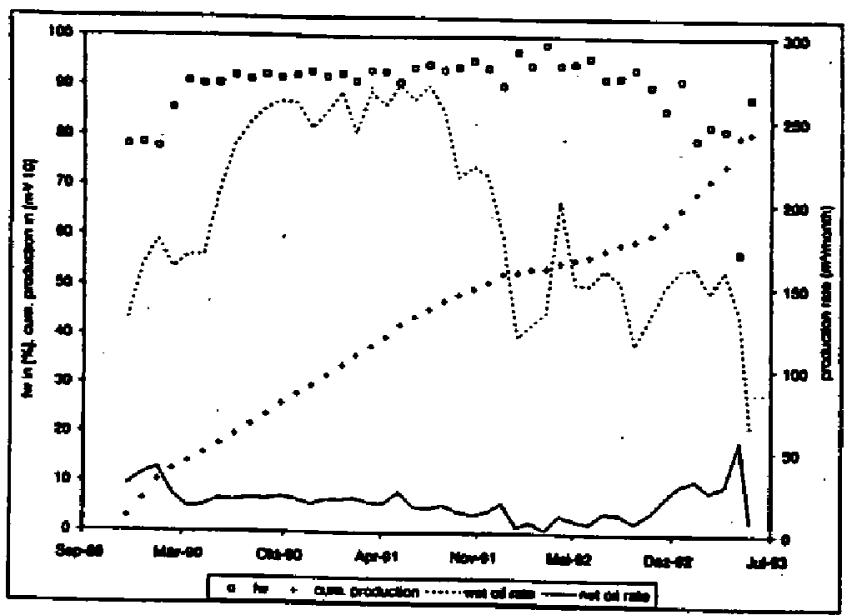

Fig. 12: Response of well 85 to polymer injection Scheerhorn
Table 3: Viscosities of different polymer samples : Scheerhorn

\begin{tabular}{|c|c|}
\hline Sample & $\begin{array}{l}\text { Viscosity in mPas } \\
\left(50^{\circ} \mathrm{C}, 3 \mathrm{~s}^{-1}\right)\end{array}$ \\
\hline Solution at well head & 27.2 \\
\hline $\begin{array}{l}\text { Solution produced from injection well } \\
\text { (after } 30 \mathrm{~m}^{3} \text { ) }\end{array}$ & 23.1 . \\
\hline Solution from production well 86 & 8.0 \\
\hline
\end{tabular}

The polymer concentration is the same for all samples (800 ppm)

Analysing the produced water from well 86 showed, that the polymer solution had still it's full concentration of $800 \mathrm{ppm}$ a short time after polymer break-through. This means, that adsorption in this case is negligible. But the viscosity of the produced xanthan solution was only $8 \mathrm{mPas}$. This is only one third of the initial viscosity. This would be approximately the same value that could have been achieved with the xanthans used in the other projects. In other words the advantage of the higher viscosity yield of the high pyruvate product was sustained only for a short time.

Table 4: Reservoir parameters and performance of the polymer projects

\begin{tabular}{|c|c|c|c|c|c|}
\hline & & Eddesse-Nord & Adorf & Vorhop-Knesebeck & Scheerhorn \\
\hline Formation & & Wealden (Sandstone) & $\begin{array}{l}\text { Valanginian } \\
\text { (Sandstone) } \\
\end{array}$ & Dogger-B (Sandstone) & $\begin{array}{l}\text { Valanginian } \\
\text { (Sandstone) } \\
\end{array}$ \\
\hline Depth & m & 290 & 1350 & 1250 & 1050 \\
\hline Temperature & ${ }^{\circ} \mathrm{C}$ & 22 & 68 & 56 & 49 \\
\hline init. resenvoir pressure & bar & 24 & 133 & 130 & 116 \\
\hline Porosity & $\%$ & 22 & 25 & 27 & 26 \\
\hline Permeability & $\mathrm{mD}$ & 600 & $2000-5000$ & 1000 & 2500 \\
\hline Thickness & $\mathrm{m}$ & 5 & 18 & 14 & 5.12 \\
\hline $\begin{array}{l}\text { Oll viscosity (Creservoir } \\
\text { conditions) }\end{array}$ & mPas & 7 & 121 & 3.5 & 30.8 \\
\hline Dead oil viscosity $\left(20^{\circ} \mathrm{C}\right)$ & mPas & 15.6 & immovable & 19 & 35000 \\
\hline init. Salinity of brine & $g i L$ & 100 & 250 & 210 & $\pi$ \\
\hline Salinity of injection water & $g / L$ & 50 & 0.112 & 210 & 77 \\
\hline Polymer & & Xanthan (Bayer) & $\begin{array}{l}\text { partially hydrolysed } \\
\text { Polyacrylamide }\end{array}$ & Xanthan (Statoil) & $\begin{array}{l}\text { Xanthan } \\
\text { (commercial) }\end{array}$ \\
\hline Polymer concentration & ppm & 1000 & \begin{tabular}{|c|}
2400 (emulsion) \\
800 (active)
\end{tabular} & $400-500$ & 800 \\
\hline $\begin{array}{l}\text { Viscosity of polymer } \\
\text { solution }(\approx 3 \mathrm{~s}-1) \text { (neser. } \\
\text { voir conditions) }\end{array}$ & mPas & 7 & 20 & 4 & 30 \\
\hline Total injected polymer & $\mathrm{kg}$ & 9450 & 639000 & 59000 & 370000 \\
\hline Pore volume & $\mathrm{m}^{3}$ & 27500 & $1+0^{6}$ & 540000 & 83000 \\
\hline OOIP & $\mathrm{m}^{3}$ & 21000 & 850000 & 450000 & 60000 \\
\hline Incremental oil recovery & $\mathrm{m}^{3}$ & 1200 & 5900 & 13400 & 2000 \\
\hline Incremental oil recovery & \%OOIP & 6 & 1 & 3 & 3.3 \\
\hline Retention/adsorption & $\mu g / g$ & $30-40$ & & 20 & \\
\hline
\end{tabular}


Another reason for the low incremental oil recovery was found in the reservoir and in it's oil. All calculations were made for an oil having a viscosity of $30 \mathrm{mPas}$ at reservoir conditions. This was only true for a short period at the beginning of production. In many parts of the field pressure was reduced to below the bubble point pressure. The production of large amounts of gas and thus the reduction of solved gas in the oil lead to an increase in oil viscosity.

Very early in the life of the field water injection had to be started in order to increase reservoir pressure. As the injection water was colder than the reservoir and large amounts of water were injected the reservoir was cooled significantly. It is estimated, that the reservoir was cooled down by about $3-5^{\circ} \mathrm{C}$. This again lead to an increase in viscosity of the oil. The oil viscosity at present is therefore not $30 \mathrm{mPas}$ but at least 60 to 100 .

\section{Conclusions}

In Table 4 the different reservoir parameters and the results of the projects are shown.

Polymer injection into the reservoirs was no problem at all. Proper mixing of the polymers could be achieved.

The retention of the polymer in the field was significantly lower than measured in the laboratory and published in different papers. This was valid for xanthan and polyacrylamide.

During all the projects the knowledge about the reservoir increased, the reservoir models had to be changed.

In the Vorhop-Knesebeck field oil recovery by water flooding was higher than anticipated at the start of the project. Therefore the oil recovery possible by polymer flooding was lower than expected at the start of the project. This was the main reason, why the project was stopped earlier than planned.

Degradation of the polymers was only small, as observed in the Eddesse-Nord, Vorhop-Knesebeck and Adorf projects. The observed "degradation" in Scheerhorn was not due to bacterial or chemical processes, but to the fact that the polymer was artificially brought to a higher apparent viscosity. The polymer came back to it's natural state in the reservoir. No change in chemical composition of the xanthan was observed for the three years of residence in the reservoir in Eddesse-Nord, where the produced polymer was intensively analysed.

The main reason for the low incremental oil recovery in the Adorf and Scheerhorn projects was, that due to economical constraints, the polymer did not have the viscosity in the reservoir it should have.

In Eddesse-Nord a xanthan degrading species of bacteria, well adapted to the conditions in the oil water separator in the field, could be isolated. However it could not degrade the xanthan significantly during the project period in the reservoir. This is due to the biocide used, the low pH-value and the high salinity in the reservoir.

\section{Literature}

[1] Littmann, W., Westerkamp, A.: "Xanthan Bjopolymer Flooding in a North German Oil Field", $4^{\text {th }}$ Eur. Symp. on Enh. Oil Rec., Hamburg, Germany, Oct. 27-29, 1987

[2] Littmann, W:, Kleinitz, W.: "Experience with Polymer Flooding in High Salinity and Low Viscosity Oil Reservoirs", $1^{\text {st }}$ Techn. Symp. on EOR. Tripoly, Libya, May 1-2, 1990

[3] Littmann, W:, Kleinith, W., Christensen, B.E., Stokke, B.T.: "Late Results of a Polymer Pilot Test: Performance, Simulation, Adsorption and Xanthan Stability in the Reservoir" 8th Symp. on Enh. Oil Rec., Apr. 22-24, 1992, Tulsa, Oklahoma, SPE/DOE 24120

[4] Kleinitz, W.; Littmann, W.; Herbst, H.: "Screening of Xanthan-Biopolymer for a High Salinity Oil Reservoir", 5th Europ. Symp. Improved Oil Recovery, 25-27 April 1989, Budapest

[5] Lund, T.; Boreng, R.; Bjomestad, E.O;; Foss,P.: "Development and testing of Xanthan Products for EOR-Application in the North Sea", 5th Europ. Symp. Improved Oil Recovery, 25-27 April 1989, Budapest

[6] Littmann, W.:"polymer flooding",Developments in petroleum Science 24, Elsevier, Amsterdam 
* Unocal, U.S.A.

** Computer Mod. Group, Canada

\begin{abstract}
Copyright 1995, Steering Committee of the European IOR - Symposium.
This peper was presented at the 8th. European IOR - Symposium in Vienna, Austria, May 15 - 17, 1996

This paper was selectod for prosentation by the steering Committee, following reviow of information conteined in an abstract submitted by the author(s). The paper, as presented has not been reviewed by the Steering Committee.
\end{abstract}

\section{ABSRACT}

Field application of foam for gas diversion was conducted in a gas condensate reservoir. The application included two years of foam injection in a single pattem, monitoring of condensate recovery in pattem producers and simulation of the process.

The primary objective of the study was to determine the effectiveness of foam in improving production response. The field, a carbonate formation with grossly varying permeability ranging between 0.1 to 20 md, had been under enriched gas drive for a number of years. Injected gas, initially nitrogen, had been gradually replaced with recycled gas. As a result, condensate yield in produced gas continued to decrease. Based on the observed gas breakthrough and somewhat adverse mobility ratio of the injected gas to the heavier in situ hydrocarbon gas, it was assumed that gas diversion from more permeable, gassed out layers could improve condensate recovery.
A single pattern, foam injection project was initiated in August of 1991. Field injectivity data collected during the first six months of the project and the gas injection history of the field, were used to construct and history match a simulation model. STARS simulator from Computer Modelling Group was used for the study. Field observed results over a two-year period were used to predict recovery from an extended project of five-year duration. Simulation was also used during the early stages of foam injection for optimization of surfactant injection.

The study showed that incremental gas condensate recovery can be obtained from foam application under appropriate mobility and heterogeneity conditions. Simulation techniques based on surfactant tracking and reduction of gas relative permeability, as used in STARS, can sufficienty model the process. Finally, inclusion of reservoir characteristics in the model at the early stages of field application can result in significant cost saving by optimizing various process parameters. 